\title{
Particulate Matter Emission Characteristics of a Biodiesel Fueled Engine at Idling Speed
}

\author{
I. Shancita, H. H. Masjuki, and M. A. Kalam
}

\begin{abstract}
Automotive and transportation sectors will be inclined towards the renewable or green energy in the near future. One of the green energy sources discovered recently is biodiesel. Biodiesel is a source of clean alternative fuel for internal combustion engines, which reduces the exhaust emissions significantly. Like diesel, biodiesel also emits exhaust particulate matter (PM), which is responsible for the black soot coming out from the diesel engine. However, it is not clear that what will be the size of PM formed during the idle speed of a biodiesel fueled engine. In this study, the characteristics of the exhaust particulate during the idling speed of a biodiesel fueled single cylinder diesel engine is analyzed. Biodiesel showed a positive result in terms of the concentration of emitted PM. However, particle sizes were smaller in case of biodiesel than diesel. Further studies should be carried out to improve the properties of biodiesel to ensure that the emitted particle sizes are not toxic to human health.
\end{abstract}

Index Terms-Biodiesel, idling, internal combustion engine, particulate matter emission.

\section{INTRODUCTION}

The ever increasing transportation demand has led to the utilization of fuel in a more efficient way. This issue has become a major concern because the fossil fuels continue to be depleted as their sources are diminishing and the price of fossil fuels keeps on increasing rapidly. Besides, the emissions from fossil fuels are the major source of environmental pollution [1]. It has been reported that the emissions from the diesel fuel may rise up to $39 \%$ by the end of 2030 if there is no regulation to limit these emissions [2]. Biodiesel has gained a mounting interest as one of the most promising answers towards the green energy source to replace reliance on fossil fuels. This is due to its potential to satisfy the energy demand, halt global warming effect and greenhouse gasses. Its primary benefits are it is biodegradable, renewable, environmental friendly and non-toxic. Biodiesel can be formulated from a diverse range of animal fats, vegetable oils or greases by dilution, pyrolysis, trans-esterification and micro-emulsion process. The biodiesel has very similar properties to the diesel fuel [3]-[6]. In the last few decades, the production of biodiesel and its performance in diesel engines have been investigated. The utilization of biodiesel in diesel engine as a blend has shown a great impact on engine performance and emissions. It was reported that biodiesel emits less PM, carbon monoxide (CO), hydrocarbons (HCs) and other emissions [7], [8]. However,

Manuscript received June 19, 2015; revised December 20, 2015.

The authors are with the Department of Mechanical Engineering, University of Malaya, 50603, Kuala Lumpur, Malaysia (e-mail shancitaislam@gmail.com, masjuki@um.edu.my,kalam@um.edu.my). usage of alternative fuels like biodiesel in diesel combustion engines can also create impact on health. This is because of the combustion related emissions from the exhaust. Vehicle idling happens when the vehicle's engine is let off to run while the transmission is not engaged. Vehicle idling has impact on human health, environment and vehicle performance too. It is a source of air pollution because of PM emissions. It also emits pollutants such as nitrogen oxide ( $\mathrm{NO} x$ ), carbon dioxide $\left(\mathrm{CO}_{2}\right)$ and volatile organic compounds (VOCs) [9], [10]. Emissions can be reduced from vehicles by turning off the engine when idle mode exceeds more than a few minutes [11]

Diesel particulates from diesel engine are a portion of the whole diesel exhaust. Two phases are put together, either gas or particle in which both of them are responsible for contributing to health risks. The gas phase in diesel exhaust emission comprises of a lot of hazardous air pollutants. Diesel particulates which are categorized as fine and ultra-fine are of the utmost health concern. Their composition may comprise of elemental carbon with absorbed composites [12], [13] PM emissions from biodiesel have been the most controversial issue due to its environmental and health anxieties. Studies in epidemiology revealed that air-borne PM has effects on a person's health. The effects include respiratory, heart diseases, and carcinogenic problems. Temperature and the type of feedstocks play an important role in the compositions of the biodiesel PM and the relation between PM characteristics and biodiesel combustion conditions are yet to be clarified. The exhaust PM size varies with engine load and speed conditions [11]. At the idle engine speed, the engine is normally operated without load. The biodiesel fueled engine normally produces lower size of particulate matter [14]. Therefore, this study is focused on how exhaust PM is formed at idle speed condition of biodiesel fueled engine as well as investigates the PM size, concentration etc. at idle speed condition of biodiesel fueled engine.

\section{Methodology}

\section{A. Experimental Setup}

An experimental measurement is conducted on YANMAR engine model TF120-M. An eddy current dynamometer was subjected to the engine and used to maintain the variation of loads at different speeds. Pure diesel (B0) and pure palm biodiesel (PB100) were used to conduct the study. Fig. 1 shows a schematic diagram of engine used for the experiment.

The engine was connected with test bed and a computer data acquisition system. Data acquisition system collects signal, rectify, filter and convert the signal to the data to be read. The data acquisition board was controlled to the laptop, 
where user can monitor, control and analysis the data using REO-dCA software. Using this software the engine was operated at idling conditions. When the engine was operated at idling conditions, engine performance and fuel consumption data were stored in the computer. For performance test, each fuel sample was tested three times and their results were averaged.

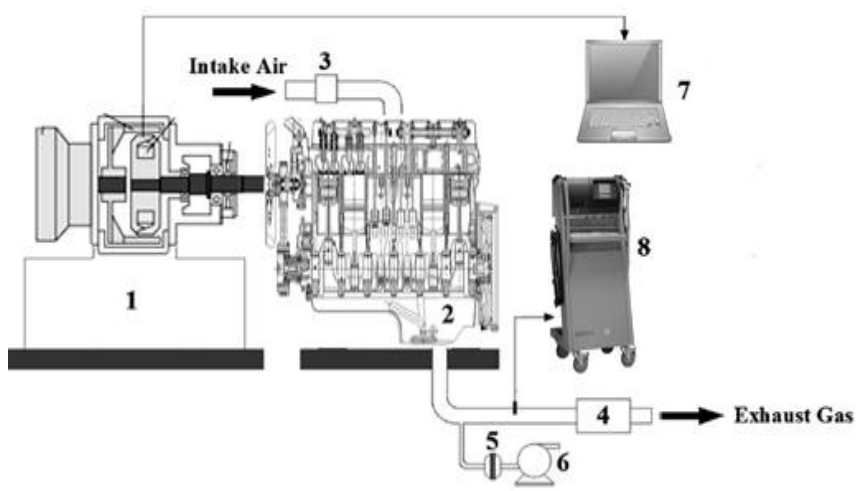

Fig. 1. Experimental layout (1: Eddy current dynamometer, 2: Diesel Engine 3: Air filter, 4: Silencer, 5: Particulate filter holder, 6: Sampling pump, 7: Dynamometer controller, 8: Portable exhaust gas analyzer).

The specification of engine was provided in Table I.

TABLE I: ENGINE SPECIFICATION

\begin{tabular}{|c|c|}
\hline Engine model & $\begin{array}{l}\text { YANMAR engine model } \\
\text { TF120-M }\end{array}$ \\
\hline Type & $\begin{array}{l}1 \text { cylinder, horizontal, water-cooled, } \\
\text { 4-cycle diesel engine }\end{array}$ \\
\hline Combustion System & Direct injection \\
\hline Aspiration & Natural aspiration \\
\hline Cylinder Bore X Stroke (mm) & $92 \times 96$ \\
\hline Displacement (L) & 0.638 \\
\hline \multirow{2}{*}{$\begin{array}{l}\text { Continuous rated } \\
\text { output }\end{array}$} & 2400 \\
\hline & 7.7 \\
\hline \multirow[t]{2}{*}{ At $1-\mathrm{hr}$ rated output } & 2400 \\
\hline & 8.8 \\
\hline Power take - off position & Flywheel side \\
\hline Starting system & Manual starting \\
\hline Cooling system & Radiator cooling \\
\hline Lubrication system & $\begin{array}{l}\text { Complete enclosed forced } \\
\text { lubricating }\end{array}$ \\
\hline
\end{tabular}

\section{B. Fuel Sampling}

When you submit your final version, after your paper has been accepted, prepare it in two-column format, including figures and tables.

Some important properties of diesel and biodiesel were tested. They are listed below in Table II.

TABLE II: PROPERTIES OF DIESEL AND BIODIESEL

\begin{tabular}{ccc}
\hline Parameter & Diesel & Palm biodiesel \\
\hline Density $(\mathbf{k g} / \mathbf{m} 3)$ & 853.8 & 878.3 \\
Viscosity $\left(\mathbf{m}^{\mathbf{2}} / \mathbf{s}\right)$ & $3.223 \times 10^{-6}$ & $4.410 \times 10^{-6}$ \\
Oxygen $(\mathbf{w t} \%)$ & 0 & 11 \\
Sulfur $\left(\times \mathbf{1 0}^{-\mathbf{6}}\right)$ & 1135 & 64 \\
Cetane number & 45 & 58.3 \\
Lower heating value & 42.59 & 38.39 \\
$(\mathbf{M J} / \mathbf{K g})$ & & \\
\hline
\end{tabular}

\section{Particulate Matter Sampling}

PM samples can be collected by many methods. In this study the particulate matter was collected from a partial-flow exhaust gas using pump with constant flow rate. Quartz filter papers were installed at the begging of diesel exhaust pipe to collect particulate matters. Filters for sampling were inserted in filter holder after the engine warmed up to $85^{\circ} \mathrm{C}$. At first diesel was fueled into the engine to determine the standard parameters. To measure fuel consumption, exhaust gas temperature, power and speed of engine, sensors were installed and data were collected. Exhaust emissions and smoke were also measured using BOSCH BEA-350 exhaust gas analyzer. In Table III, specifications of exhaust gas analyzer are presented.

TABLE III: EXHAUST GAS ANALYZER SPECIFICATION

\begin{tabular}{ll}
\hline Equipment Name & BOSCH BEA-350 Exhaust Gas Analyzer \\
\hline Measured HC & Parts per million (ppm) \\
Carbon monoxide & Percentage volume (\%vol) \\
Carbon dioxide & Percentage volume (\%vol) \\
Smoke & Percentage opacity (\%opac) \\
\hline
\end{tabular}

\section{Particle Size and Elemental Composition}

Particle sizes were measured using SEM model -3400N at $5000 x$ magnification. The acceleration voltage of the microscope while operating was $10 \mathrm{KV}$. Elemental composition of the sample has been analyzed by energy dispersive system at 5000x magnification (HORIBA EMAX EDX) attached to the microscope. Each sample was scanned at three different spots.

\section{RESULTS AND DISCUSSION}

\section{A. Engine Performance}

The engine was tested under 2 idling conditions at engine speeds of $1500 \mathrm{rpm}$ and $2000 \mathrm{rpm}$. The operating conditions are listed in Table IV.

\begin{tabular}{ccc}
\multicolumn{3}{c}{ TABLE IV: ENGINE } \\
\hline Fuel & Mode & Engine speed (rpm) \\
\hline B0 & 1 & 1500 \\
& 2 & 2000 \\
PB100 & 3 & 1500 \\
& 4 & 2000 \\
\hline
\end{tabular}

\section{B. Engine Torque and Power}

Fig. 2 represents the torque and the power of the engine at the two operating conditions for both of the fuels. From the figure, it can be observed that torque decreased slightly by approximately $3 \mathrm{Nm}$ with increasing engine speed of $500 \mathrm{rpm}$. Torque of the engine can decrease due to two main factors. One is the lowered volumetric efficiency of the engine because of the increase in engine speed. The other factor is thought to be expansions in mechanical losses. On the other hand, reduction in engine power was found while using biodiesel (B100).This result is expected for B100 compared to diesel (B0) due to its respective lower heating value. Insignificant average power reductions of biodiesel compared 
to diesel were found as $1.6 \%$ and $0.56 \%$ at $1500 \mathrm{rpm}$ and $2000 \mathrm{rpm}$ respectively.

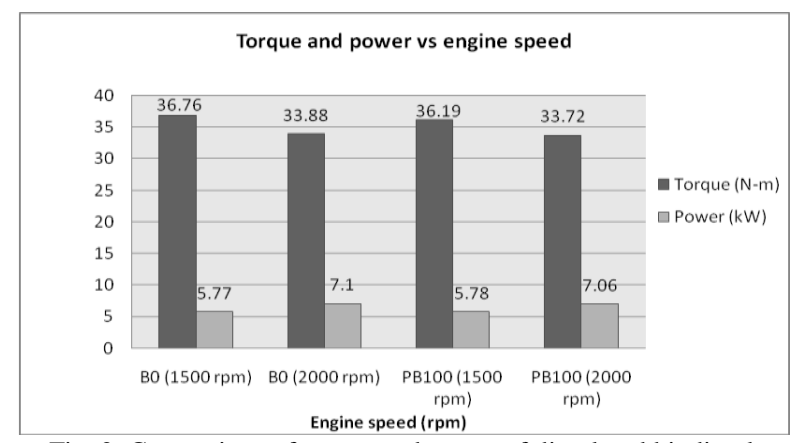

Fig. 2. Comparison of torque and power of diesel and biodiesel.

\section{Engine Exhaust Temperature}

Fig. 3 shows the variations of exhaust gas temperatures for the two different fuels. Diesel (B0) was found to have the highest exhaust gas temperature (EGT) value at all tested conditions. However, biodiesel showed a decrease in EGT by $15.8 \%$ and $2.01 \%$ at $1500 \mathrm{rpm}$ and $2000 \mathrm{rpm}$ respectively. The reduction is significant at $1500 \mathrm{rpm}$ whereas there is only a slight decrease at $2000 \mathrm{rpm}$. Heating value, cetane number, density and kinematic viscosity, these four physicochemical properties have potential impact on EGT. Biodiesel showed lower EGT than diesel due to higher cetane number, higher viscosity and density and lower heating value. Lower EGT is an indication of good burning of fuel inside cylinder combustion chamber.

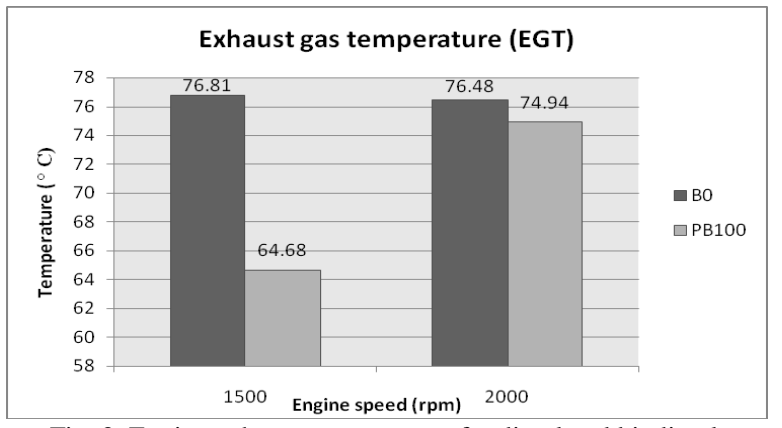

Fig. 3. Engine exhaust temperatures for diesel and biodiesel.

\section{Diesel Particles Size}

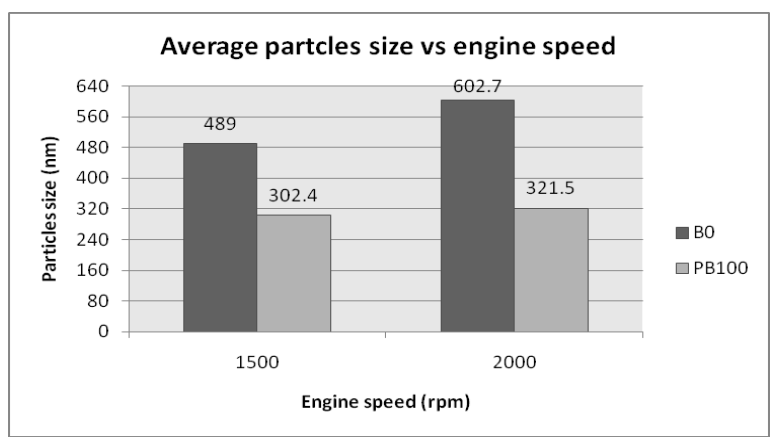

Fig. 4. Average particles size for diesel and biodiesel.

Presently, the PM regulation is mainly dependent on emitted particle mass and concentration. Many studies have been conducted and they proved that biodiesel produces less PM emission. However, more attention has been paid to particle size in terms of air quality as it is believed that toxicity increases with decreasing particle size. Using biodiesel as alternative fuel is negative in terms of particle size. Fig. 4 shows the average diameter of particles with respect to engine speed. It can be noted that palm biodiesel (PB100) produced smaller diameter of particles in average compared to diesel (B0). The size of particles increased with engine speed for both fuels tested.

\section{E. Effect of Pure Diesel (BO) on Particles Size}

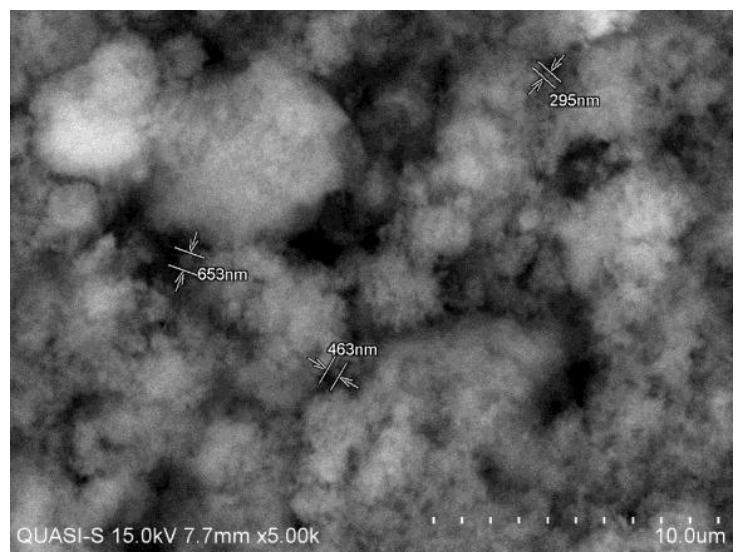

(a)

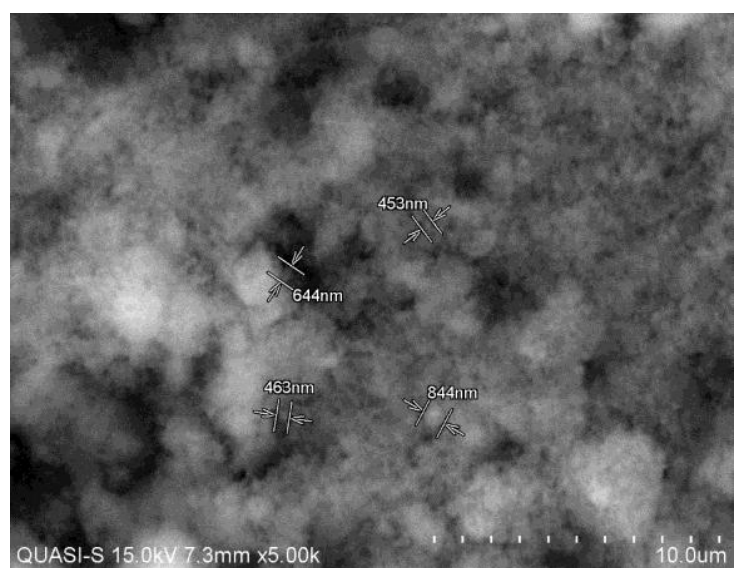

(b)

Fig. 5. SEM image for diesel PM at (a) $1500 \mathrm{rpm}$ and (b) $2000 \mathrm{rpm}$.

Fig. 5 represents SEM images of two different locations for diesel which has been taken at two different engine speeds. The average of particles size was about $489 \mathrm{~nm}$ at $1500 \mathrm{rpm}$ and $602.7 \mathrm{~nm}$ at $2000 \mathrm{rpm}$. It can be seen from Fig. 5 that, size of the particle increased with increasing engine speed. Concentration of diesel particles also increased, with more accumulated particles can be seen in the image when the speed was increased.

\section{F. Effect of Pure Biodiesel (PB100) on Particles Size}

Exhaust particles and engine performance are affected by biodiesel. Biodiesel resulted a reduction in overall particle sizes compared to diesel. Fig. 6 shows particles distribution at different engine speeds for palm biodiesel. The average particle size was about $302.4 \mathrm{~nm}$ at $1500 \mathrm{rpm}$ and $321.5 \mathrm{~nm}$ at $2000 \mathrm{rpm}$. As the speed increased, it can be seen that more accumulated particles were formed.

Particles of less than $50 \mathrm{~nm}$ diameter are usually referred to as the nucleation mode, which is the smallest group of particles. The formation of such particles is occurred either by 
homogeneous nucleation in the atmosphere or by nucleation processes which is the result of emissions from high temperature sources and lead to the emission of primary nucleation mode particles. Because of the highly diffusive nature of such particles they have a relatively transient existence in the atmosphere and they readily transform into larger particles and also deposit quite efficiently on surfaces. This happens due to their low individual mass and high tendency to Brownian motion. The growth of nucleation mode particles is occurred primarily by vapor condensation process but is also influenced by coagulation process. Those processes lead to the formation of particles of the accumulation mode that are generally between $50 \mathrm{~nm}$ and $1 \mu \mathrm{m}$ in size. As they do not coagulate rapidly like fine and coarse particles, their further growth is inhibited and there are diffusion barriers to their growth by condensation [15]-[17].

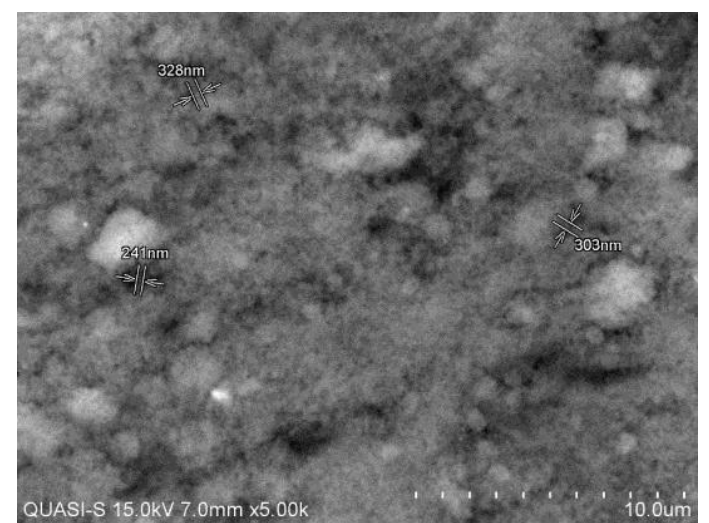

(a)

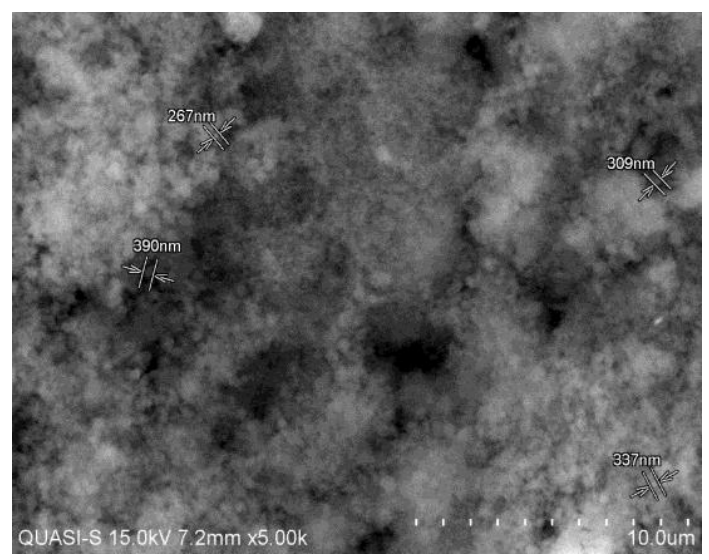

(b)

Fig. 6. SEM image for palm biodiesel PM at (a) $1500 \mathrm{rpm}$ and (b) $2000 \mathrm{rpm}$.

Biodiesel produces significantly smaller particle sizes in average due to its higher oxygen content and cetane number. High cetane number of biodiesel decreases the ignition delay time and the premixed combustion and influences the generation of more nucleation mode particles in the pre-combustion. The higher oxygen content of the biodiesel optimizes later diffusion combustion process and inhibits the transformation of particles from nucleation mode to accumulation mode.

\section{G. Elemental Analysis of Particulate Compositions}

Carbon is the main element in the particles that have been released from diesel engine; particles of carbon are coated by organic and inorganic substances. From EDX energy dispersive system, the elemental compositions of the samples are as followed.

1) Elemental analysis of diesel particulate matter emission

Fig. 7 shows the composition of diesel PM at $1500 \mathrm{rpm}$ and $2000 \mathrm{rpm}$. EDX data from 3 spots of each sample showed that the diesel PM consist of Carbon (C), Oxygen (O), and Fluorine $(\mathrm{F})$ contents. The filter mainly consists of Carbon $(\mathrm{C})$ and Fluorine $(\mathrm{F})$ content, with only a small percentage of Oxygen $(\mathrm{O})$ content.

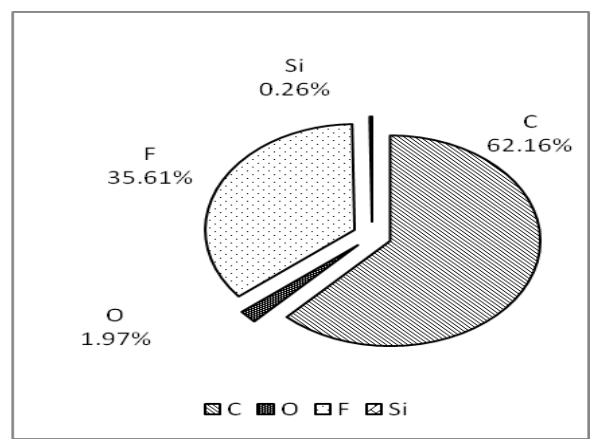

(a)

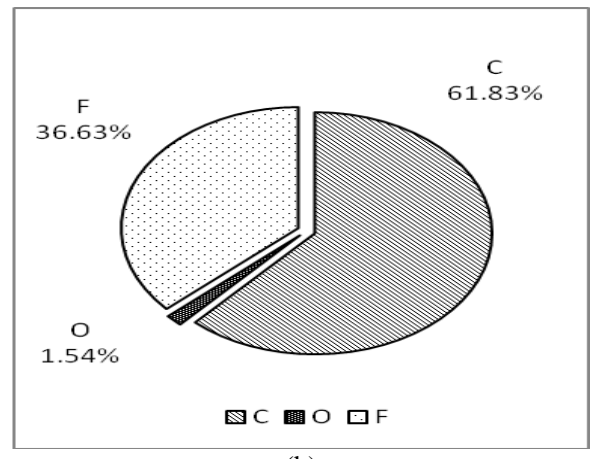

(b)

Fig. 7. Element composition of diesel PM at (a) $1500 \mathrm{rpm}$ (b) $2000 \mathrm{rpm}$.

Carbon $(\mathrm{C})$ and Oxygen $(\mathrm{O})$ content in the PM decreased as the speed of the engine increased. Increasing engine speed cause better mixing of air and fuel to provide complete combustion, utilizing more Carbon $(\mathrm{C})$ and Oxygen $(\mathrm{O})$. Meanwhile, the Fluorine (F) content increased. Oxygen (O) percentage was low mainly due to the fact that they didn't settle on to the particles.

2) Elemental analysis of palm biodiesel particulate matter emission

The elemental composition of the palm biodiesel (PB100) did not contain any particulates of Silicon ( $\mathrm{Si}$ ). Fig. 8 shows the elemental composition for biodiesel PM at $1500 \mathrm{rpm}$ and $2000 \mathrm{rpm} .3$ spots that has been analyzed consisted of Carbon (C), Oxygen (O), and Fluorine (F) contents. The Carbon (C) and Fluorine $(\mathrm{F})$ contributed the most in the biodiesel PM. Carbon $(\mathrm{C})$ and Oxygen $(\mathrm{O})$ content in the PM decreased as the speed on the engine increased. The trend was similar to the diesel PM. However, the Carbon $(\mathrm{C})$ and Oxygen $(\mathrm{O})$ in biodiesel PM were slightly lower than diesel PM at both conditions. This is given by the fact that biodiesel has a lower carbon content and high oxygen content which provided more complete combustion to give out less carbon in particles. Fluorine (F) content increased in biodiesel PM. 


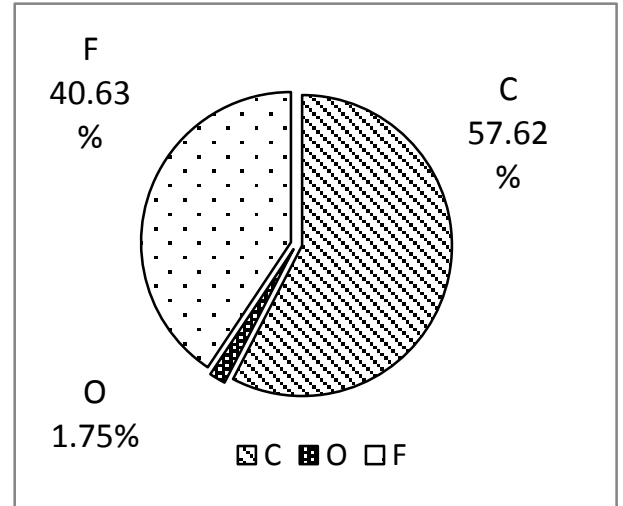

(a)

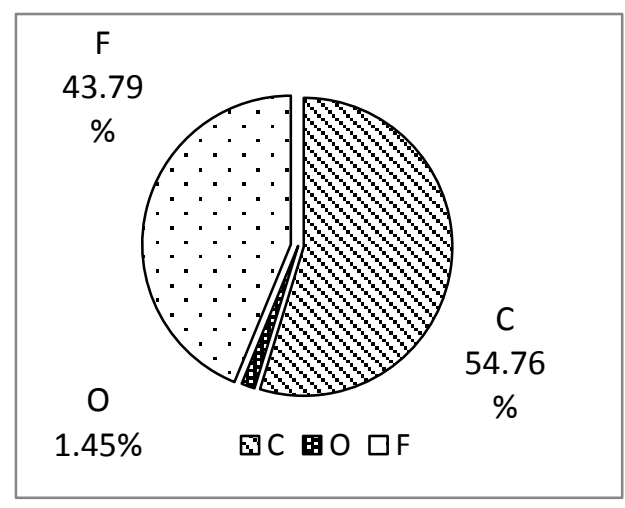

(b)

Fig. 8. Element composition of palm biodiesel PM at (a) $1500 \mathrm{rpm}$ (b) 2000 rpm.

\section{CONCLUSION}

In this study several operating conditions have been set under idling state at different speeds. Biodiesel has been selected due to its properties to reduce the amount of particulate matter from the exhaust emission of the engine. Details from SEM images has been provided; results have been compared with diesel fuel in terms of engine performance, regulated emissions, PM emissions and total size of the particles matter. Some conclusions can be drawn from this study. For example, biodiesel (B100) produces lower engine power than diesel fuel (B0) at all operating conditions. Biodiesel (B100) produces lower concentration of particulate matter (PM) than diesel fuel (B0) at all operating conditions. Biodiesel (B100) and diesel (B0) produce particle sizes in range of accumulation mode of nano-particles. Biodiesel (B100) produces significantly smaller particle sizes in average than diesel (B0) at all operating conditions. In terms of particulate composition, only Carbon (C), Oxygen $(\mathrm{O})$, and Fluorine $(\mathrm{F})$ contents are found in particles for both fuels. Biodiesel (B100) shows lower Carbon (C) and Oxygen (O) contents in the particles at all operating conditions than diesel (B0).

\section{RECOMMENDATIONS}

$\mathrm{PM}$ is one of the major pollutants emitted by diesel engines. The concentration of PM decreases when using biodiesel, however the size of particles are more refined and their sizes are becoming more toxic to the human health. Biodiesel negatively affects the particles size but positively affects the particle concentration in the smoke. It is recommended that more studies should be done on biodiesel properties so that the particles size, that are emitted are much larger, and can be filtered. Though their concentration is found lower, but their sizes are gaining more attention. A recent study found that nano-particles are more hazardous to human health than larger particles and also affects atmospheric visibility. These particles also have a long atmospheric lifetime, typically 7-30 days, although they are subjected to removal by incorporation into rain and this can significantly shorten their atmospheric lifetime [14], [15].

\section{ACKNOWLEDGMENT}

The authors would like to acknowledge University of Malaya for financial support through High Impact Research grant UM.C/HIR/MOHE/ENG/07.

\section{REFERENCES}

[1] M. Mofijur, H. Masjuki, M. Kalam, M. Hazrat, A. Liaquat, M Shahabuddin, and M. Varman, "Prospects of biodiesel from Jatropha in Malaysia," Renewable and Sustainable Energy Reviews, vol. 16, no. 7, pp. 5007-5020, 2012.

[2] M. Mofijur, H. Masjuki, M. Kalam, A. Atabani, M. Shahabuddin, S. Palash, and M. Hazrat, "Effect of biodiesel from various feedstocks on combustion characteristics, engine durability and materials compatibility: A review," Renewable and Sustainable Energy Reviews, vol. 28, pp. 441-455, 2013.

[3] M. Shahabuddin, A. Liaquat, H. Masjuki, M. Kalam, and M. Mofijur, "Ignition delay, combustion and emission characteristics of diesel engine fueled with biodiesel," Renewable and Sustainable Energy Reviews, vol. 21, pp. 623-632, 2013.

[4] S. A. Basha and K. R. Gopal, "A review of the effects of catalyst and additive on biodiesel production, performance, combustion and emission characteristics," Renewable and Sustainable Energy Reviews, vol. 16, no. 1, pp. 711-717, 2012.

[5] S. P. Singh and D. Singh, "Biodiesel production through the use of different sources and characterization of oils and their esters as the substitute of diesel: A review," Renewable and Sustainable Energy Reviews, vol. 14, no. 1, pp. 200-216, 2010.

[6] M. Jayed, H. Masjuki, R. Saidur, M. Kalam, and M. I. Jahirul, "Environmental aspects and challenges of oilseed produced biodiesel in Southeast Asia," Renewable and Sustainable Energy Reviews, vol. 13, no. 9, pp. 2452-2462, 2009.

[7] J. Sheehan, V. Camobreco, J. Duffield, M. Graboski, and H. Shapouri, "Life cycle inventory of biodiesel and petroleum diesel for use in an urban bus," U.S. Department of Energy's Office of Fuels Development and U.S. Department of Agriculture's Office of Energy, 1998.

[8] M. M. Roy, W. Wang, and J. Bujold, "Biodiesel production and comparison of emissions of a DI diesel engine fueled by biodiesel-diesel and canola oil-diesel blends at high idling operations," Applied Energy, vol. 106, pp. 198-208, 2013.

[9] S. A. Rahman, H. H. Masjuki, M. A. Kalam, M. J. Abedin, A. Sanjid, and H. Sajjad, "Production of palm and Calophyllum inophyllum based biodiesel and investigation of blend performance and exhaust emission in an unmodified diesel engine at high idling conditions," Energy Conversion and Management, vol. 76, pp. 362-367, 2013.

[10] I. Shancita, H. H. Masjuki, M. A. Kalam, I. M. Rizwanul Fattah, M. M Rashed, and H. K. Rashedul, "A review on idling reduction strategies to improve fuel economy and reduce exhaust emissions of transport vehicles," Energy Conversion and Management, vol. 88, pp. 794-807, 2014.

[11] H. Omidvarborna, A. Kumar, and D. S. Kim, "Characterization of particulate matter emitted from transit buses fueled with B20 in idle modes," Journal of Environmental Chemical Engineering, vol. 2, no. 4, pp. 2335-2342, 2014.

[12] J. E. Johnson and D. B. Kittelson, "Deposition, diffusion and adsorption in the diesel oxidation catalyst," Applied Catalysis B: Environmental, vol. 10, no. 1, pp. 117-137, 1996.

[13] D. H. Lowenthal, J. C. Chow, J. G. Watson, G. R. Neuroth, R. B. Robbins, B. P. Shafritz, and R. J. Countess, "The effects of collinearity 
on the ability to determine aerosol contributions from diesel-and gasoline-powered vehicles using the chemical mass balance model," Atmospheric Environment. Part A. General Topics, vol. 26, no. 13, pp. 2341-2351, 1992.

[14] K. K. Shandilya and A. Kumar, "Physical characterization of fine particulate matter inside the public transit buses fueled by biodiesel in Toledo, Ohio," Journal of hazardous materials, vol. 190, no. 1, pp. 508-514, 2011.

[15] J. Bünger, M. M. Müller, J. Krahl, K. Baum, A. Weigel, E. Hallier, and T. G. Schulz, "Mutagenicity of diesel exhaust particles from two fossil and two plant oil fuels," Mutagenesis, vol. 15, no. 5, pp. 391-397, 2000.

[16] E. P. Agency, "A comprehensive analysis of biodiesel impacts on exhaust emissions," US Environmental Protection Agency, Washington DC, 2002.

[17] H. Yamada, K. Misawa, D. Suzuki, K. Tanaka, J. Matsumoto, M. Fujii, and K. Tanaka, "Detailed analysis of diesel vehicle exhaust emissions: Nitrogen oxides, hydrocarbons and particulate size distributions," Proceedings of the Combustion Institute, vol. 33, no. 2, pp. 2895-2902, 2011.

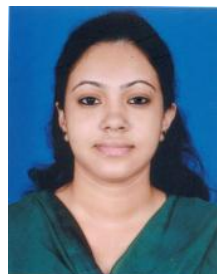

I. Shancita obtained her B.Sc. of mechanical engineering degree in 2013 from Bangladesh University of Engineering \& Technology, BUET. Currently, she is working as a research assistant in the Centre for Energy Sciences under the supervision of Prof. Dr. Masjuki Bin Hj. Hassan and Dr. Md. Abul Kalam. She is also enrolled as a postgraduate student at the Department of Mechanical Engineering to pursue her master of engineering science degree in University of Malaya Her research interests are in biodiesel, internal combustion engine, renewable energy and automobiles. She published one ISI ranked review paper on the sector of idling reduction technologies of transport vehicles.

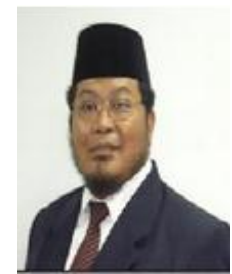

H. H. Masjuki obtained his B.Sc. of mechanical engineering degree, at Leeds University, Leeds U.K. in 1977. He continued his M.Sc. in tribology and $\mathrm{Ph} . \mathrm{D}$. degrees from the same university and graduated in 1978 and 1982 respectively. Upon the completion of his studies, he was being appointed as a lecturer in 1983 at University of Malaya. He is currently appointed as the professor at Mechanical Engineering Department, University of Malaya. He is also one of the senate members of University of Malaya and a secretary of Council of National Professors-Engineering and Technology cluster. He is the founding president of Malaysian Tribology Society (MyTRIBOS) and the director of the Centre for Energy Sciences.

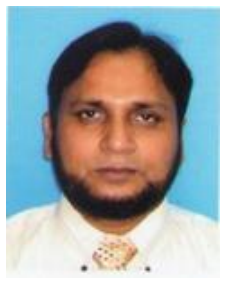

M. A. Kalam is working as a senior lecturer in the Department of Mechanical Engineering, University of Malaya since 2008 to date. His research specialization is on internal-combustion engine, biodiesel/biofuel, lubricant testing and engine tribology. Dr. Kalam obtained his undergraduate degree from Bangladesh Institute of Technology (B.I.T) Khulna, Bangladesh, presently known as KUET, Bangladesh, and master \& $\mathrm{Ph}$.D. degrees from University of Malaya, Malaysia. 